\title{
Dynamic and Elastic Response of Aircraft in Gust Loads
}

\author{
Yi Zhang ${ }^{1}$, Lei Deng ${ }^{2}$, Gang Sun ${ }^{1, *}$ and Xiangzheng $\mathrm{Tu}^{3}$ \\ ${ }^{1}$ Department of Aeronautics \& Astronautics, Fudan University, 200433 Shanghai, PR China \\ ${ }^{2}$ China COMAC Shanghai Aircraft Design and Research Institute, 201210 Shanghai, PR China \\ ${ }^{3}$ State Key Laboratory of Civil Aircraft Flight Simulation, 201210 Shanghai, PR China \\ ${ }^{*}$ Corresponding author
}

\begin{abstract}
Aeroelastic response of gust is always an important problem in flight quality assessment. In this study, structure and aerodynamic solvers based on Lagrange equation and Euler equation are coupled with loose coupling method. Elastic general-purpose airplane and a high-aspect-ratio transport airplane with elastic wings are simulated. The simulations proved the capacity of the method and studied the dynamic response in gust with different conditions.
\end{abstract}

Keywords—gust load; aircraft; dynamic; aeroelasticity

\section{INTRODUCTION}

Aeroelastic problems have restricted the development of aircraft since the invention of fixed-wing aircraft. In 1903, 9 days before the Wright brothers made the first successful biplane flight, professor Langley took flight test with power of monoplane (Air Traveler). Because of the shortage of wing torsional rigidity, divergence of static torsion destroyed the wings. The importance of aeroelasticity problem in aircraft design process has been widely noticed. With the development of aviation industry, the requirement of aircraft performance has become increasingly higher. According to the European air transport development route document "Flightpath 2050", reducing carbon emission and improving aerodynamic performance will be an important direction of future civil aviation industry. Based on above demands of transport aircraft, high-aspect-ratio wing is undoubtedly one of the most promising solutions because of low structure weight, high liftto-drag ratio. In high-aspect-ratio wing, wings are flexible. Elastic aircraft is always influenced by disturbance of gust wind when flying in the air. Gusts produce determinate or random additional aerodynamic loads, which cause the rigid body motion and elastic vibration of the aircraft. The structure safety, flight performance and attack accuracy of the aircraft can be affected when the value of gust amplitude is too large. So it is important to analyze the structure and dynamic response in gust wind.

Compared with wind tunnel test and flight test, gust analysis with numerical calculation method is economic and time-saving. Problems of the deign can be found at the beginning. Fransesco built a flexible aircraft model of dynamics and aeroelasticity based on finite element method ${ }^{[1]}$. Marcelo derived the mathematical model of flexible transport category aircraft ${ }^{[2]}$. Based on general body axes, Antonio analyzed the flight dynamics response of flexible aircraft ${ }^{[3]}$. In terms of gust response, Haim Abramovich tested the dynamic response of a high aspect ratio wing with PZT patches theoretically and experimentally ${ }^{[4]}$. Yonghui Zhao analyzed the aeroelastic gust response of large transport airplane in the frequency domain and build the gust load alleviation (GLA) controller for that ${ }^{[5]}$.

In this work, Von Karman and Dryden turbulence models and 1-cosine gust models are reviewed. Calculation models of elastic structure response and aerodynamic analysis are coupled with loose coupling method. Then the models of a generalpurpose airplane and a high-aspect-ratio transport airplane are simulated to demonstrate the method. And the dynamic responses in different gust are studied.

\section{Wind AND TURBUlENCE MODELS}

An elastic aircraft is inevitably affected by disturbances in atmosphere. Gusts are prevalent in the atmosphere. On the wind speed profile, gusts are always manifesting as deviations of wind speed. The descriptions of gusts generally include discrete gusts models and continuous turbulence models. The former represent the deterministic wind speed change. The latter represent the indeterminate turbulent flow of the atmosphere. They are always presented as random functions with continuous waveform and frequency.

\section{A. Von Karman Model}

Von Karman derived the energy spectrum function of atmosphere turbulence:

$$
E(\Omega)=\sigma^{2} \frac{55 L}{9 \pi} \frac{(\alpha L \Omega)^{4}}{\left[1+(\alpha L \Omega)^{2}\right]^{17}}
$$

$\sigma$ is turbulence intensity. $\mathrm{L}$ is turbulence scale. $\Omega$ is spatial frequency spectrum. $\alpha$ equals to 1.339. Energy spectrum function accord with limitation conditions: when $\Omega \rightarrow 0, \mathrm{E} \propto$ const; when $\Omega \rightarrow \infty, \mathrm{E} \propto \Omega^{-5 / 3}$.

Spatial frequency spectrum of atmosphere turbulence:

$$
\phi(w)=\frac{1}{v} \phi(\Omega)=\frac{1}{v} \phi\left(\frac{w}{v}\right)
$$


Vertical spatial frequency spectrum can be derived into temporal spectrum:

$$
\Phi_{w w}(\omega)=\sigma_{w}{ }_{w} \frac{L_{w}}{\pi V} \frac{1+\frac{8}{3}\left(\alpha L_{w} \frac{\omega}{V}\right)^{2}}{\left[1+\left(\alpha L_{w} \frac{\omega}{V}\right)^{2}\right]^{\frac{11}{6}}}
$$

$\Phi_{\mathrm{ww}}$ is temporal spectrum. $\omega$ is frequency. The Von karman model is built in the form of power spectrum. It can not be applied to flight simulation directly. In this paper, the turbulent flow is simulated by the method of estimating the linear filter rational spectral method by rational power spectrum method. Taking vertical turbulence for example, simulation method of the Von karman turbulence model is studied. Taking white noise as input, proper system function is selected to make input power spectrum of system equal to Von Karman model.

Based on fundamental of linear system:

$$
S_{w}(\omega)=|H(\omega)|^{2} S_{r}(\omega)
$$

$\mathrm{S}_{\mathrm{r}}(\omega)$ and $\mathrm{S}_{\mathrm{w}}(\omega)$ is power spectral density of input and output response. $H(\omega)$ represent frequency response function. It equals to root of Von Karman power spectrum to make statistic characteristics of turbulence velocity. Taking white noise process as input, result is:

$$
S(\omega)=\Phi_{w w}(w)=\sigma_{w}{ }_{w} \frac{L_{w w}}{\pi V} \frac{1+\frac{8}{3}\left(\alpha L_{w} \frac{\omega}{V}\right)^{2}}{\left[1+\left(\alpha L_{w} \frac{\omega}{V}\right)^{2}\right]^{\frac{11}{6}}}
$$

Based on:

$$
\Phi(w)=\frac{1}{V} \Phi(\Omega)=\frac{1}{V} \Phi\left(\frac{\omega}{V}\right)
$$

Spatial frequency spectrum can be converted into temporal spectrum:

$$
\Phi_{v v}(\omega)=\sigma_{v}{ }^{2} \frac{L_{v v}}{\pi V} \frac{1+\frac{8}{3}\left(2 a L_{v} \frac{w}{V}\right)^{2}}{\left[1+\left(2 a L_{v} \frac{w}{V}\right)^{2}\right]^{\frac{11}{6}}}
$$

$$
\Phi_{w w}(\omega)=\sigma_{w}{ }^{2} \frac{L_{w w}}{\pi V} \frac{1+\frac{8}{3}\left(2 a L_{w} \frac{w}{V}\right)^{2}}{\left[1+\left(2 a L_{w} \frac{w}{V}\right)^{2}\right]^{\frac{11}{6}}}
$$

\section{B. Dryden Model}

The Dryden model is a type of linearized turbulence models. One-dimensional Dryden spectrum of vertical atmosphere turbulence is taken. Its power spectral density is:

$$
\Phi_{w}(\omega)=T \sigma^{2} \frac{1+3 T^{2} \omega^{2}}{\left(1+T^{2} \omega^{2}\right)^{2}}
$$

Where $\mathrm{T}$ is the ratio of length of turbulence and velocity. $\sigma$ is the strength of turbulence. $\omega$ is circular frequency. It is a rational spectrum and can be linearized directly. The linearized state space of the vertical atmosphere turbulence can be obtained:

$$
\left\{\begin{array}{c}
\dot{Z}=\left[\begin{array}{cc}
0 & 1 \\
-1 / T^{2} & -2 / T
\end{array}\right]\left[\begin{array}{l}
Z_{1} \\
Z_{2}
\end{array}\right]+\left[\begin{array}{l}
0 \\
1
\end{array}\right] r \\
W=\left[\begin{array}{ll}
\sigma T^{-3 / 2} & \sqrt{3 / T} \sigma
\end{array}\right] \cdot\left[\begin{array}{l}
Z_{1} \\
Z_{2}
\end{array}\right]
\end{array}\right.
$$

$\mathrm{Z}$ is the state parameter of atmosphere turbulence. $\mathrm{r}$ is white Gaussian noise whose mean value is 0 and variance is 1 .

\section{Discrete Gust Model}

In flight quality evaluation, strength calculation and flight control, it is regulated that the profile of gust wind should be in the form of 1-cosine. There are two kinds of discrete gust wind models are widely used. Gust wind model of full-wavelength is commonly used before 1980s while half-wavelength discrete gust model is more preferred after 1980s. Taking aircraft as reference system, the profiles of wind speed are showed in Figure I and Figure II.

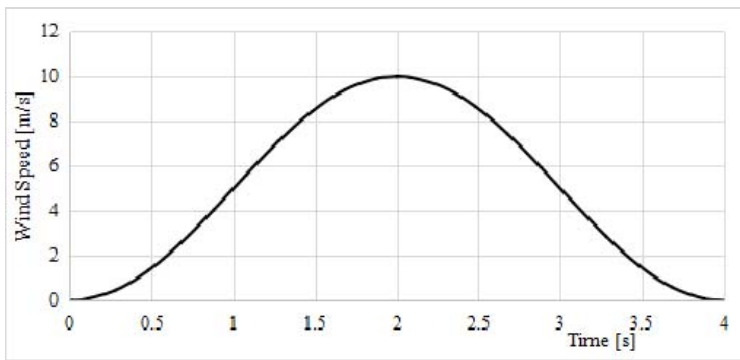

FIGURE I. FULL-WAVELENGTH GUST WIND MODEL 


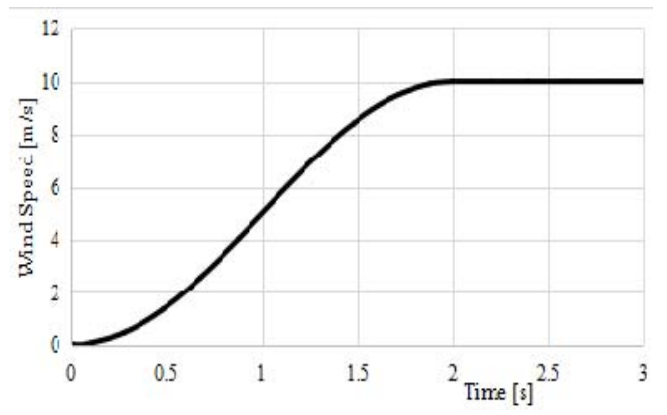

FIGURE II. HALF-WAVELENGTH GUST WIND MODEL

\section{CAlCUlation Methods}

\section{A. Structure Model}

Dynamic and structure models of general elastic aircraft can be obtained from Lagrange equation:

$$
\frac{d}{d t}\left(\frac{\partial T}{\partial q_{i}}\right)-\frac{\partial T}{\partial q_{i}}+\frac{\partial\left(U_{g}+U_{e}\right)}{\partial q_{i}}=Q_{i}
$$

Where $T$ is the total kinetic energy of aircraft. $q_{i}$ is generalized degrees of freedom which include 6 degrees of rigid motion freedom and all elastic deformation. $\mathrm{Q}_{\mathrm{i}}$ is the generalized force. $U_{g}$ and $U_{e}$ is gravity potential energy and elastic potential energy respectively. The equations of these parameters are:

$$
\begin{gathered}
T=\frac{1}{2} M\left(U^{2}+V^{2}+W^{2}\right)+\frac{1}{2}\left[\begin{array}{lll}
p & q & r
\end{array}\right]\left[\begin{array}{l}
\mathbf{I}
\end{array}\right]\left[\begin{array}{l}
p \\
q \\
r
\end{array}\right]+\frac{1}{2} \int_{V} \frac{d \mathbf{p}}{d t} \frac{d \mathbf{p}}{d t} \rho d V \\
U_{g}=-M g z \\
U_{e}=-\frac{1}{2} \int_{V} \frac{\delta^{2} \mathbf{d}}{\delta t^{2}} \cdot \mathbf{d} \cdot \rho d V
\end{gathered}
$$

Where $\mathrm{U}, \mathrm{V}, \mathrm{W}$ are the velocities of gravity center. $\mathrm{M}$ is the mass of aircraft. p, q, r are angular velocity components on body axis system. I is the matrix of rotational inertia. $\mathbf{p}$ is the coordinate of mass element in body axis system. $(\mathrm{x}, \mathrm{y}, \mathrm{z})$ is gravity center position in ground coordinate. $\mathrm{g}$ is acceleration of gravity. d is displacement vector of mass element. According to structural dynamics, elastic deformation of structure can be represented by vibration mode and coordinate of generalized displacement:

$$
\mathbf{d}=\sum_{i=1}^{\infty} \boldsymbol{\varphi}_{i}(x, y, z) \eta_{i}(t)
$$

Thus kinetic energy and elastic potential energy are:

$$
\begin{gathered}
T=\frac{1}{2} M\left(U^{2}+V^{2}+W^{2}\right)+\frac{1}{2}\left[\begin{array}{lll}
p & q & r
\end{array}\right]\left[\begin{array}{l}
\mathbf{I}
\end{array}\right]\left[\begin{array}{l}
p \\
q \\
r
\end{array}\right]+\frac{1}{2} \sum_{i=1}^{\infty} M_{i} \eta_{i}^{2} \\
U_{e}=-\frac{1}{2} \sum_{i=1}^{\infty} \omega_{i}^{2} \eta_{i}^{2} M_{i}
\end{gathered}
$$

Substitute these equations into Lagrange equation. Dynamic response of external force is determined by these equations.

\section{B. Aerodynamic Model}

The aerodynamic model is built based on 3-d Euler equation:

$$
\frac{\partial(\rho u)}{\partial t}+(\rho u \cdot \nabla) u=\rho f-\nabla p
$$

$$
\frac{\partial \rho}{\partial t}+u \cdot \nabla \rho=0
$$

The aerodynamic loads on wing is calculated previously by panel method. In simulation, momentary value of loads are obtained by interpolation functions.

\section{Aerodynamic/Structure Coupling}

Aerodynamic loads and structure response can be calculated with separated tools in loose coupling analysis. Coupling is carried out through exchange of information on the interface of fluid and structure, such as load, displacement and speed. Therefore, the loose coupling method can maintain independence of various solvers. Existing CSD and CFD method can be fully utilized. It is only needed to build a relevant data exchange module. The complexity of calculation is reduced and the explicit/implicit processing is simplified. Therefore, loose coupling strategy is widely used in the study of aerodynamic-structure interaction.

In loose coupling method, structure and the aerodynamic solver solve structural dynamics equations and the fluid flow control equations respectively. Integration in time domain is made and information is transmitted alternatively. As the Figure III shows, it is supposed that structure and fluid parameters at $\mathrm{n}$ moment have been obtained. 


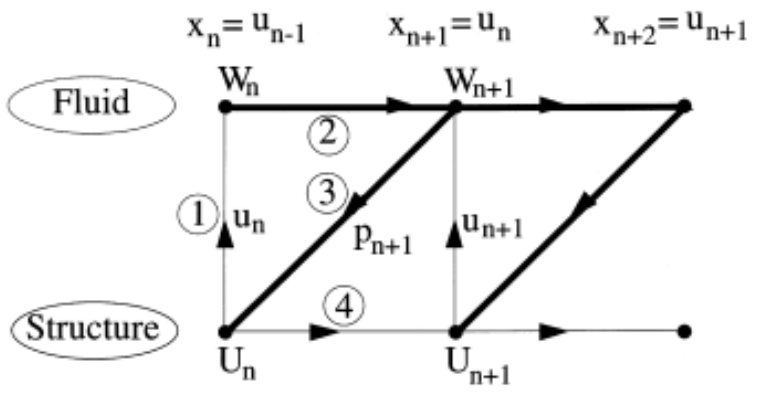

FIGURE III. AERODYNAMIC/STRUCTURE COUPLING

1 The structure deformation at $\mathrm{n}$ moment transmitted to the aerodynamic model;

2 Loads at $n+1$ moment are calculated by aerodynamic model;

3 Structure responses are obtained with the updated loads in structure model;

4 Repeat step 1 into the next cycle.

\section{Model of an Elastic General-Purpose Airplane}

In this section, a type of elastic aircraft model with straight wing, backswept horizontal tail and backswept vertical fin is simulated in full wavelength discrete gust. The finite element model of aircraft is showed in Figure IV. The length of fuselage is 322 feet. The length of span is 360 feet.

The first 20 modes of aircraft's nature vibration is showed in Table I and Figure V. The frequency of first 6 modes are motion modes. Thus frequencies are 0 .

Based on exciting of a gust, calculation results of overload acceleration of gravity center is showed in Figure VI while load on gravity center of aileron is in Figure VII.

TABLE I. NATURE FREQUENCY

\begin{tabular}{cccccc}
\hline & 1 & 2 & 3 & 4 & 5 \\
frequency & 0 & 0 & 0 & 0 & 0 \\
\hline & 6 & 7 & 8 & 9 & 10 \\
frequency & 0 & 0.28054 & 0.57705 & 0.61248 & 0.64726 \\
\hline & 11 & 12 & 13 & 14 & 15 \\
frequency & 0.92327 & 0.96161 & 0.97266 & 1.2124 & 1.3976 \\
\hline & 16 & 17 & 18 & 19 & 20 \\
frequency & 1.4407 & 1.4826 & 1.7508 & 1.8018 & 1.8647 \\
\hline
\end{tabular}

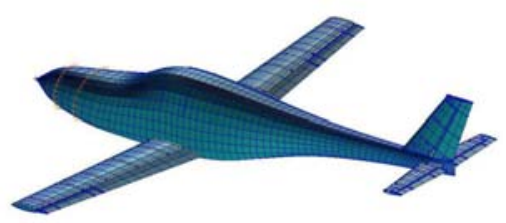

FIGURE IV. FINITE ELEMENT MODEL OF AIRCRAFT

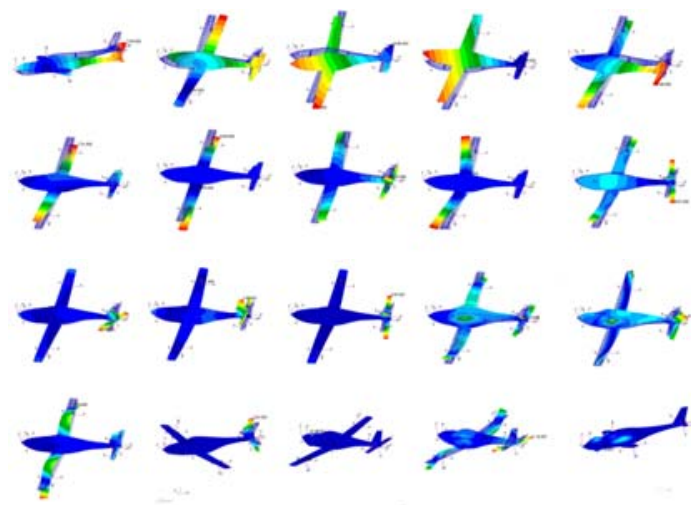

FIGURE V. NATURE MODE

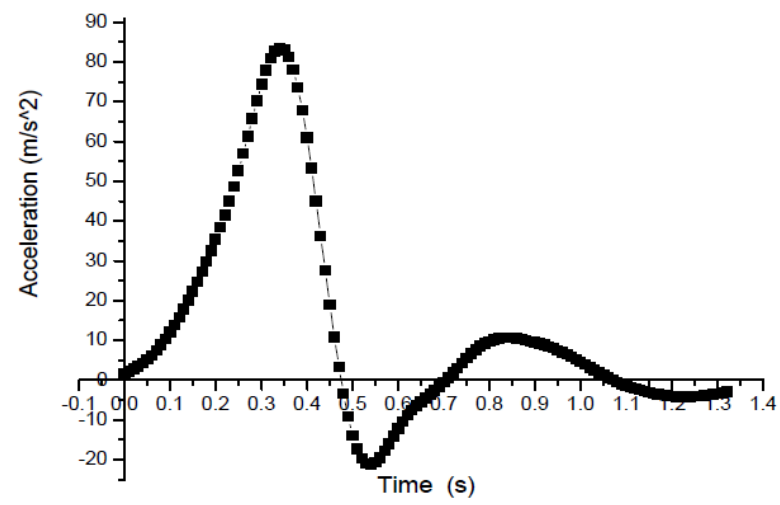

FIGURE VI. ACCELERATION OF GRAVITY CENTER

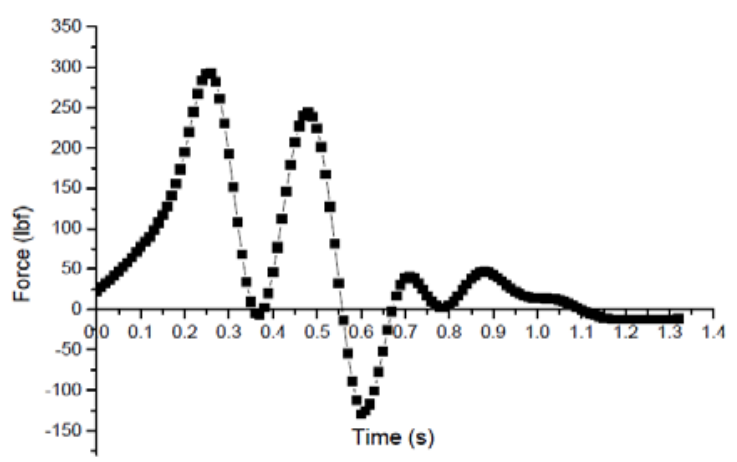

FIGURE VII. LOAD ON GRAVITY CENTER OF AILERON

\section{Elastic High-AsPeCt-Ratio Transport Airplane}

In this section, flight simulation model of a type of highaspect-ratio airplane is built. The aircraft model is showed in Figure VIII. Torsion and bending stiffness of fuselage is much higher than wings and tails because of the geometry profile. Tails are small. Aeroelastic influence is small. So only wings are elastic parts to be concerned. In terms of wind model, Dydren continuous turbulence model and discrete gust in form of half-wavelength.

In this case, the wing model is concerned as a cantilever beam. The beam is divided in 20 elements. Finite element 
method is used to calculate the nature frequency and mode. The results of first 5 modes are showed in Table II.

During the simulation, the vertical displacement of wing tip and attack angle of aircraft are showed in Figure IX and Figure $X$. The wing tip vibrate with long and short periods simultaneously. The amplitude of long-periodic vibration is large at first because of discrete gust. Then it fade and becomes stable with the stabilization of attack angle and flight state. In response of discrete gust, long-periodic vibration dominates the wing deformation while response of continuous turbulence is more related with short-periodic modes.

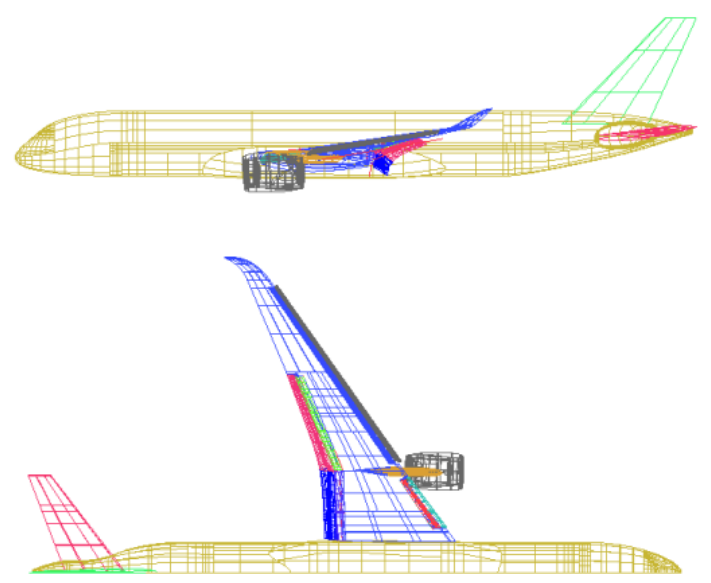

FIGURE VIII. AIRCRAFT MODEL

TABLE II. NATURE FREQUENCY OF FIRST 5 MODES

\begin{tabular}{cc}
\hline & Frequency(Hz) \\
\hline 1 & 4.174465902 \\
2 & 12.6089618 \\
3 & 26.49702311 \\
4 & 47.9643925 \\
5 & 76.55320263
\end{tabular}

Moreover, the relationship between gust response with flight height and gust length are concerned with the results showed in Figure XI and Figure XII. With the increase of flight height, aerodynamic force of gust wind reduce gradually because of decrease of air density. Finally, these accelerations are stabilized on different value. In Figure XII, shorter gust length make more influence on airplane and sharper peaks on acceleration profile. At last, these profiles converged to one curve.

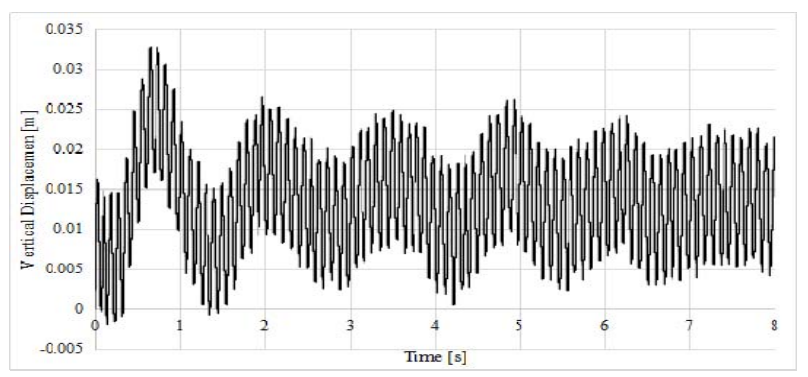

FIGURE IX. TIME-VERTICAL DISPLACEMENT OF WING TIP

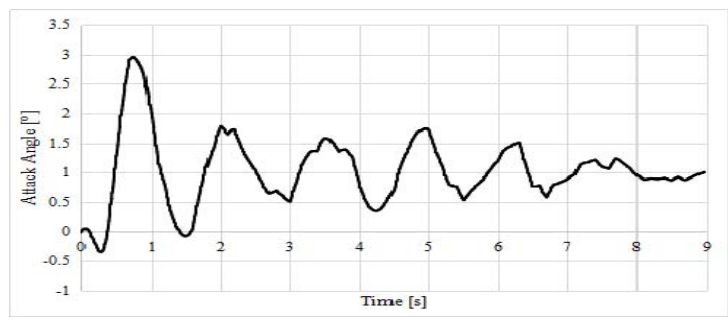

FIGURE X. ATTACK ANGLE OF AIRCRAFT

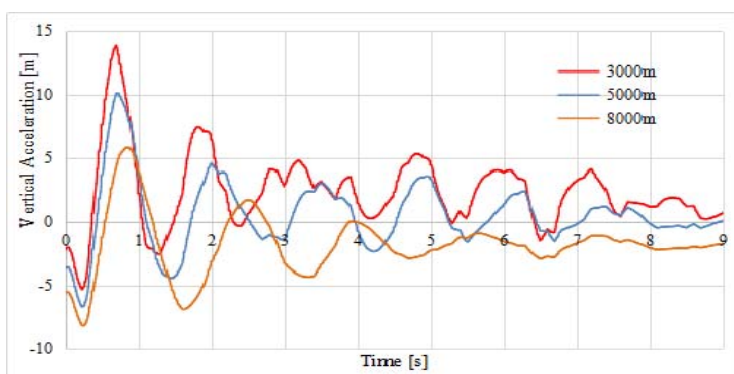

FIGURE XI. FLY HEIGHT-VERTICAL ACCELERATION OF GRAVITY CENTER

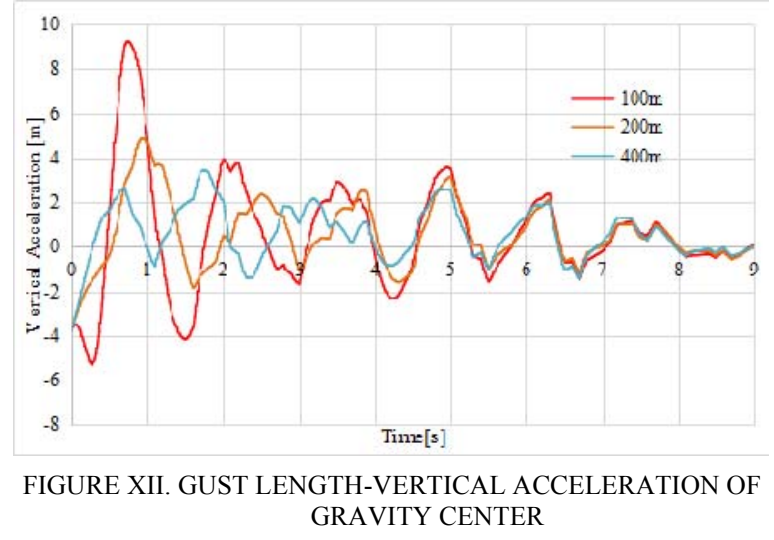

\section{CONCLUSION}

In this paper, calculation method of gust response is built by coupling structure and dynamic solver with loose coupling method. Nature modes of two elastic aircraft are calculated. And the dynamic responses of these 2 aircraft in full-length and half-length gust wind are simulated. Moreover, during the simulation, aircraft responses of gust wind reduce with the increase of flight height. And shorter gust length make more influence on airplane and sharper peaks on acceleration profile.

Currently, there are a large number of control methods to do gust alleviation. It is valuable to consider the influence of flight state on gust alleviation controller. Moreover, more precise solvers and coupling methods are not adopted. Some more complex nonlinear phenomenons are neglected here.

\section{REFERENCES}

[1] Francesco, S., Cristina, R., Guido, D., M., and Franco M., "FiniteElement-Based Modeling for Flight Dynamics and Aeroelasticity of Flexible Aircraft," Journal of Aircraft, Vol. 54, No. 6, Jun. 2017, pp. 2350-2366. 
[2] Marcelo, S., S., Pedro P., Roberto, G., A., S., Flavio, L., C., R., Sebastiao, S., C., "Mathematical model of one flexible transport category aircraft," Aircraft Engineering and Aerospace Technology, Vol. 89, Issue: 3, pp.384-396

[3] Antonio, B., G., N., Roberto, G. A. S., Pedro, P., Flavio, J., S., "Formulation of the Flight Dynamics of Flexible Aircraft Using General Body Axes,” AIAA Journal, Vol. 54, No. 11 (2016), pp. 3516-3534.

[4] Haim, A., Tanchum, W., and Siow, Y., P., "Dynamic Response of a High Aspect Ratio Wing Equipped with PZT Patches - A Theoretical and Experimental Study," Journal of Intelligent Material Systems and Structures, Vol. 16, Jan. 2005, pp. 919-923.

[5] Yonghui, Z., Chengyu, Y., and Haiyan, H., "Gust Load Alleviation on a Large Transport Airplane,” Journal of Aircraft, Vol. 53, No. 6, Nov.-Dec. 2016, pp. 1932-1946. 